\section{Validation study on new isothermal container for hot ready to eat food in catering establishments: Preliminary results}

\author{
Marta Castrica, ${ }^{1}$ Katia Razzini, ${ }^{2}$ \\ Sara Panseri, ${ }^{1}$ Claudia M. Balzaretti ${ }^{1}$ \\ ${ }^{1}$ Department of Health, Animal Science \\ and Food Safety "Carlo Cantoni" \\ (VESPA), Università degli Studi di \\ Milano; ${ }^{2}$ U.N.P.I.S.I., Florence, Italy
}

\begin{abstract}
The production methods, in particular the cook-serve method, applied in high production catering establishments, even if inserted in a correct spatial design, it is affected by time-temperature flows characterized by inadequate designed moments during which critical points can be observed. The aim of this study was to evaluate, at a preliminary stage, how the new technologies can support the supply chain and production processes in catering establishments. To this end, a specific passive and active heat storage system was tested: "Polibox Smart Heater ${ }^{\circledR}$ " (PX SH), which makes an isothermal expanded polypropylene container an advanced maintainer for ready to eat food. The experimental design was divided into four different experiments, during which the functionality of the isothermal containers was evaluated, and thermal-tightness tests were carried out. The results showed that the PX SH containers, containing a heat accumulator, are temperature maintainers, which guarantee thermal stability $\left(>65^{\circ} \mathrm{C}\right)$, according to the current standard (UNI EN 12571:1999). In conclusion, the production chain of catering establishments should use innovative technologies such as PX SH, in order to benefit from performance consistent with the safety, hygiene and sensory criteria.
\end{abstract}

\section{Introduction}

Food safety concerns have existed for a long time, as millions of people across the globe suffer from food borne disease every year (Moreb et al., 2017). Contamination of food owing to limited knowledge of food safety practices and in particular as regard "cook-serve method" primarily increases the risk of food borne illnesses (Moreb et al., 2017). Food-borne zoonoses represent a serious threat to public health worldwide.
More than 320.000 human cases are reported annually in the European Union (EU), although the actual number is likely to be much higher (EFSA, 2016).

As regard foodborne illnesses, in 2016 Italy reported the highest number of outbreaks in the last 5 years $(\mathrm{N}=91)$, an increase of $146 \%$ compared to 2015 . (EFSA, 2016).

As far as the place of onset is concerned, domestic environment represents the context in which foodborne illnesses episodes have most often occurred (58\%), followed by public catering $(19 \%)$ and lastly collective catering (8\%) (DeLind and Howard, 2008).

On one hand, a quality catering service requires a complex organizational action based on the interaction between different professional figures, including professionals in the field of nutrition and food safety (Griffith, 2000).

On the other hand, given the complexity of the structures involved, the vulnerability of the users to whom it is addressed and the scale of the consequences of possible pathological events associated with it is clear how important vigilance and control are, which, in order to be effective, must be carried out with method and rigor; for these reasons a careful planning is of strategic importance to ensure food safety and nutritional quality (Pichler et al., 2014).

In this context, the production processes, in particular the cook-serve method, in their apparent simplicity of production reserve for operators in the catering sector numerous disadvantages that give rise to a poor-quality performance of production and a potential area of microbiological risk during which critical points are observed due to a lack of knowledge of principles: timetemperature and physics i.e. the second principle of thermodynamics.

The second principle of thermodynamics states that heat cannot spontaneously pass from a colder to a warmer body and that many thermodynamic events, such as the passage of heat from a hot body to a cold one, are irreversible, and the entropy of an isolated system far from thermal equilibrium tends to increase over time, until equilibrium is reached (Ozawa et al., 2003).

The production methods, in particular the cook-serve method, applied in high production catering establishments, even if inserted in a correct spatial design, they are affected by time-temperature flows characterized by inadequate designed moments during which critical points can be observed. As suggested in HACCP systems, good manufacturing practice procedures and the Accord Transport Perissable, respect for the hot chain requires that meals
Correspondence: Marta Castrica, Department of Health, Animal Science and Food Safety, University of Milan, via Celoria 10, 20133 Milan, Italy.

Tel. +39.050317857

E-mail: marta.castrica@unimi.it

Key words: cook-serve method, catering establishments, polibox smart heater ${ }^{\circledR}$.

Acknowledgements: the authors would like to thank Dr. Marina Messina (Studi Marina Messina Consulting) and Eng. Marco Malasomma (DRYCE s.r.1.).

Contributions: The authors contributed equally.

Conflict of interest: The authors declare no potential conflict of interests.

Funding: None

Availability of data and materials: The data that support the findings of this study are available from the corresponding author upon reasonable request.

Ethics approval and consent to participate: This research was conducted in accordance with all relevant guidelines and procedures.

Consent for publication: The manuscript does not contain any individual person's data in any form.

Received for publication: 19 July 2019.

Revision received: 18 October 2019.

Accepted for publication: 27 October 2019.

This work is licensed under a Creative Commons Attribution-NonCommercial 4.0 International License (CC BY-NC 4.0).

(C) Copyright: the Author(s), 2020

Licensee PAGEPress, Italy

Italian Journal of Food Safety 2020; 9:8417

doi:10.4081/ijfs.2020.8417

are kept at a temperature of not less than $60^{\circ} \mathrm{C}$, from the moment of cooking, during packaging, transport and distribution until the moment of consumption. Moreover, no more than two hours must elapse between the end of cooking and the time of consumption (Ratkowsky et al., 1982).

These requirements are indispensable in order to avoid the risk of microbial growth. If either of these requirements were not met, the possibility of bacterial multiplication would increase, thus the foodborne disease risk, besides the fact deterioration of the sensory quality of food would deteriorate. Therefore, the respect of hot chain prevents food from deteriorating in order to maintain the chemical, physical, organoleptic and nutritional properties of the food, in addi- 
tion minimize the microbiological risk (Marzano and Balzaretti, 2011). At present, for the transport of hot ready to eat food from catering establishments to remote consumption sites are used isothermal containers made of expanded polypropylene (EPP). EPP is suitable for food use, is non-toxic, does not give off odors or flavors to food and is easily washable, as well as recyclable (Brody et al., 2008). Moreover, EPP has high performance in terms of both thermal insulation and mechanical resistance. This material also has a high resistance to chemicals and high temperatures (up to about $120^{\circ} \mathrm{C}$ ) (Limbo and Piergiovanni, 2010). In addition, the high temperature resistance of EPP allows containers to be washed in the dishwasher, making washing operations comfortable and ensuring high cleanliness and hygiene for subsequent reuse, without retaining odors (Brody et al., 2008).

The aim of this study was to test and validate in the preliminary phase an innovative model of isothermal containers in EPP that has several advantages over existing ones, in order to include new technologies in the supply chain to support production processes. The design of the flows should always be in function of the technical characteristics of the equipment, the time-temperature parameters and the physical principles that govern the thermal balance.

\section{Materials and Methods}

An isothermal container in EPP (Figure 1) for the transport of hot ready to eat food was examined, equipped with an innovative system (patent pending) for the accumulation of active/passive heat. The system called "Smart Heater" consists of modulating and self-regulating electric heaters, coupled with ceramic-plastic accumulators and an anodized-aluminium radiating surface certified for food contact. The classic EPP container is thus transformed into a real heat maintainer for ready-to-eat food which, by exploiting both the heat of the food and the heat produced autonomously, charges the thermal accumulators to stabilize the temperature inside the container at $65^{\circ} \mathrm{C}$. Taking advantage of the physical rules of the second principle of thermodynamics, it uses the accumulators as thermal "flywheels", releasing heat at different intensities and speeds, only when the temperature inside the container drops below $65^{\circ} \mathrm{C}$.

\section{Experimental Design}

The tests were conducted on EPP isothermal containers delivered to the laboratory of microbiology and food inspection (VESPA) on arrival each container was identified by a specific ID number, the con- tainers used in the experiment contained three steel gastronorm, $10 \mathrm{~cm}$ deep.

The experimental design was divided into four different trials.

\section{Trial 1: conformity of the container with the declared technical characteristics}

The functionality of the containers was evaluated in accordance with the user's manual and the time required to reach the operating temperature $\left(65^{\circ} \mathrm{C}\right)$ was monitored; in addition, the temperature coherence detected by container was evaluated with those recorded by a certified data logger (Testo Saveris, model: T2D, calibrated by Certified Calibration Laboratories).

\section{Trial 2: containers thermal-tightness}

The thermal insulation quality of the container when used in active mode has been assessed, and

thermal tightness tests were carried out with detection by means of three certified data loggers (Testo Saveris, model: T2D, calibrated by Certified Calibration Laboratories), positioned in the geometric centre of the GN 1/1 format gastronorm in steel with a height of $10 \mathrm{~cm}$. At the end of the experiment the data of the loggers were downloaded; i.e. reading/recording every 15 minutes.

\section{Trial 3: thermographic test}

A thermographic test was carried out to verify the "value" of the design and industrialization of the heaters, accumulators and radiating plate coupling. From the moment the heaters of the container were switched on, for a period of 1 hour and 30 minutes, at 10-minute intervals, thermographic images were taken inside the empty container. At the end of the process, 2 further experiments were carried out: (i) Experiment without gastronorms and food: thermaltightness test (temperature decay) of the container equipped with 3 empty steel gastronorm GN 1/1 format, height $10 \mathrm{~cm}$ at room temperature $\left(+25^{\circ} \mathrm{C}\right)$; (ii) Experiment with gastronorms full: thermal-tightness test (temperature decay) of the container equipped with three gastronorm GN 1/1 format, height $10 \mathrm{~cm}$ each containing $5.5 \mathrm{~kg}$ of water heated to the initial temperature of about $+75^{\circ} \mathrm{C}$ at room temperature $\left(+25^{\circ} \mathrm{C}\right)$. Figure 2 shows the positioning of the gastronorm and temperature transducers inside the container used during the experiments.

\section{Trial 4: thermal-tightness test of the con- tainers with food}

The impact and implications of the containers on ready to eat food (hot meals) were evaluated; the container was brought to temperature by ignition in the early morning $\left(\right.$ T. $\left.65.0^{\circ} \mathrm{C}\right)$. The container was disconnected from the mains and taken to the catering establishment with a transport time of about 30 minutes, when it was switched on again it was at $57.6^{\circ} \mathrm{C}$. On arrival at the catering establishment, the container was reconnected to the power supply and brought back to a temperature of $65^{\circ} \mathrm{C}$ before introducing the gastronorms with food.

Three steel gastronorms GN 1/1, $10 \mathrm{~cm}$ deep, completely filled with food and siled with their lids, were introduced in the PX $\mathrm{SH}$ in the following way: a first dish in the medium position, a second dish in the highest position and a side dish in the lowest position. The container loading was carried out in about 1.5 minutes. After loading, the container display reported a temperature loss of about $2-3^{\circ} \mathrm{C}$. The temperatures were measured by means of three certified data loggers (Testo Saveris, model: T2D, calibrated by Certified Calibration Laboratories), positioned in the geometric centre of the gastronorms (immersed in the food). The container remained attached to the mains for 1 hour. It was then disconnected and moved by a vehicle suitable for the food transport to the microbiology and food inspection laboratory (VESPA). At the end of the experiment (after 3 hours) the container was reconnected to the mains electrical outlet, the temperature visible on the container display was $60.1{ }^{\circ} \mathrm{C}$, while the

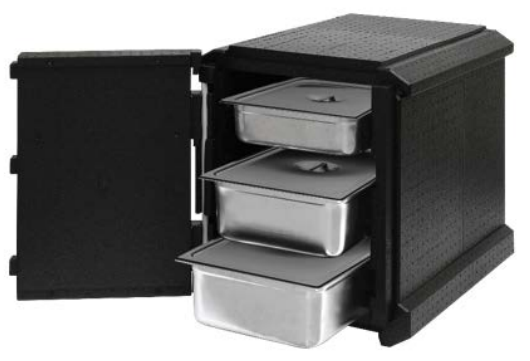

Figure 1. Isothermal container in expanded polypropylene (Polibox Smart Heater $\left.{ }^{\circledR}\right)$.

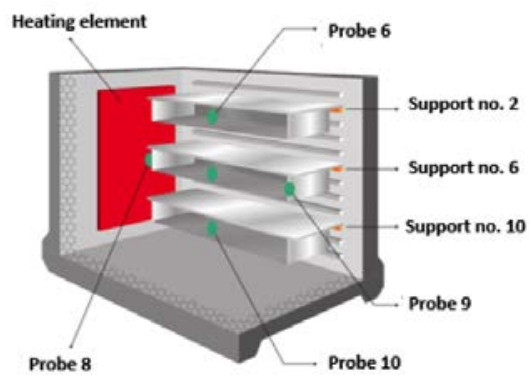

Figure 2. Thermal transducers position. 
temperature on the data logger (Testo Saveris, model: T2D, calibrated by Certified Calibration Laboratories) display located near the container's probe was $59.5^{\circ} \mathrm{C}$. The data of the loggers set to a $\mathrm{read} / \mathrm{record}$ period of 2 minutes were downloaded.

\section{Results}

\section{Trial 1: conformity of the container with} the declared technical characteristics

The experiment has shown that, following the manufacturer's instructions, the container reaches a temperature of $65^{\circ} \mathrm{C}$ within the set time and the consumption, when switched on, of 150 Watt decreases progressively as the internal temperature of the container increases until it settles at 30/40 Watt when the operating temperature is reached $\left(+65^{\circ} \mathrm{C}\right)$.

\section{Trial 2: containers thermal-tightness}

The results of this experiment have demonstrated excellent thermal resistance (Figure 3). A slight temperature difference between the bottom and top of the container was detected.

\section{Trial 3: thermographic test}

Figure 3 show the results of the thermographic test that demonstrates the efficiency of the coupling of heaters/thermal accumulators/radiating plate and has reconfirmed the characteristics of thermodynamic transmission detected in trial 2.

\section{Trial 4: thermal-tightness tests of the con- tainers with food}

Table 1 shows the results of the thermal-tightness test with food (standard use). The data shows that the container is a highperformance temperature maintainer. Thanks to the thermal accumulators, they are able to maintain the temperature stable $\left(+65^{\circ}\right)$ and the experimentation has shown within three hours that there is in compliance with UNI EN 12571:2009.

\section{Discussions}

The results showed that isothermal containers, equipped with purposely made heat accumulators, are temperature maintainers, which ensure thermal stability $\left(>65^{\circ} \mathrm{C}\right)$, according to the UNI EN 12571:1999 standard. The results of the experiments show that the thermal flywheel obtained thanks to the coupling of heater, thermal accumulators and radiating plate, transforms the EPP container into an excellent temperature maintainer that guarantees consistent thermal stability and greater equal to $65^{\circ} \mathrm{C}$, fully satisfying the regulations in force. The data shows that in active mode the power consumption is low. This results in considerable energy savings, with undisputed advantages both from the economic point of view and in terms of environmental sustainability (Goodland, 1995).

In fact, the self-regulating heat generation system, capable of producing and modulating thermal energy, combined to heat storing mediums, to aid the generation medium and restore the desired temperature, avoids unnecessary energy waste in accordance with the guidelines of the European Union on circular economy and energy sustainability (Haas et al., 2005).
Furthermore, the use of EPP for its intrinsic characteristics as well as ensuring high performance in terms of thermal insulation, has a closed cell structure that provides excellent characteristics of protection from impact. A positive feature of the material is also its recyclability with respect to the current environmental issue (Hahladakis et al., 2018).

\section{Benefits for food supply chain and economic impacts}

The standard EPP containers without the system of accumulation of active/passive heat, often do not make it possible to respect that the hot chain not fall below $60^{\circ} \mathrm{C}$, in order to ensure that, different conditions should be satisfied:

The hot meals $\left(>60^{\circ} \mathrm{C}\right)$ should be placed in the EPP container immediately after the preparation;

The EPP container should be completely filled to ensure good temperature maintenance;

The EPP container, once filled and closed, cannot be opened until arrival at the point of administration.

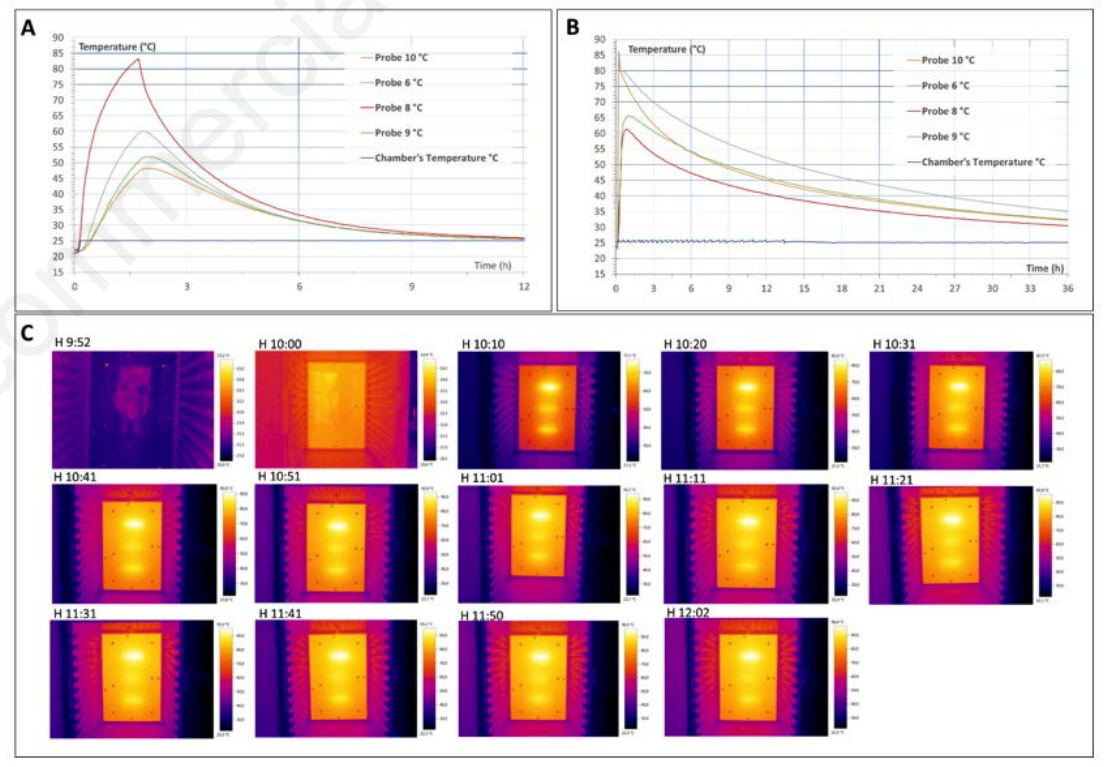

Figure 3. A)Experiment without gastronorms and food; B) Experiment with gastronorms full; C) Results of the thermographic test.

Table 1. Results of the thermal-tightness test with food (standard use).

\begin{tabular}{lccc} 
Detection Time & Highest Position $\left(\mathrm{T},{ }^{\circ} \mathrm{C}\right)$ & Lowest Position $\left(\mathrm{T},{ }^{\circ} \mathrm{C}\right)$ \\
\hline 11:45:00 & 67,1 & 64,4 & 58,3 \\
$12: 45: 00$ & 78,1 & 65,5 & 58,7 \\
\hline $13: 45: 00$ & 74,6 & 64,3 & 58 \\
$14: 45: 00$ & 71,6 & 62,6 & 56,3 \\
\hline
\end{tabular}


The transport time should be short between the production centre and the point of administration in order to avoid temperature decays;

The time between the arrival of the meal at the point of administration and its distribution for consumption should be brief.

The management of all these variables can create critical points along the flow, with consequent development of moments of thermal abuse inside the containers and therefore temporary interruption of the hot chain. This situation may lead to possible microbiological hazards and changes in the sensory properties of meals.

For these reasons, the use of a new isothermal container in EPP, equipped with an innovative system for the accumulation of active/passive heat, allow to avoid these possible risks by bringing benefits to the food supply chain.

Moreover, the combination of a generator able to produce a modulable flow rate of thermal energy, together with an accumulator capable of constantly releasing the energy allow to maintain the correct temperature, avoiding energy wastage, with multiple economic benefits from energy savings. Finally, the accumulator of active/passive heat, as a whole is an economical and durable device with good mechanical properties.

\section{Conclusions}

In conclusion, the production chain of catering establishments should use this highly innovative technology in order to benefit from performance consistent with the hygiene safety and sensory criteria, thus offering end users highest quality food. Having said that, it should be considered that the design of the flows shall take into account the specifics of the production site as well as the technical characteristics of the equipment in use and the time-temperature parameters associated with the physical principles that govern the thermal balance.

\section{References}

Moreb NA, Priyadarshini A, Jaiswal AK, 2017. Knowledge of food safety and food handling practices amongst food handlers in the Republic of Ireland. Food Control 80:341-9.

EFSA, 2016. The European Union summary report on trends of zoonoses, zoonotic agents and food-borne outbreaks in 2016. EFSA J 15:5077.

DeLind LB, Howard PH, 2008. Safe at any scale? Food scares, food regulation, and scaled alternatives. Agric Human Values 25:301-17.

Griffith C, 2000. Food safety in catering establishments. M Tech Food Sci Technol 235-256.

Pichler J, Ziegler J, Aldrian U, Allerberger F, 2014. Evaluating levels of knowledge on food safety among food handlers from restaurants and various catering businesses in Vienna, Austria 2011/2012. Food Control 35:33-40.

Ozawa H, Ohmura A, Lorenz RD, Pujol T, 2003. The second law of thermodynam- ics and the global climate system: A review of the maximum entropy production principle. Rev Geophys 41.

Ratkowsky DA, Olley J, McMeekin TA, Ball A, 1982. Relationship between temperature and growth rate of bacterial cultures. J Bacteriol 149:1-5.

Marzano MA, Balzaretti CM, 2011. Cookserve method in mass catering establishments: Is it still appropriate to ensure a high level of microbiological quality and safety? Food Control 22:1844-50.

Brody AL, Bugusu B, Han JH, Sand CK, Mchugh TH, 2008. Innovative food packaging solutions. J Food Sci 73:10716.

Limbo L PS, Piergiovanni L, 2010. Food Packaging. Materiali, Tecnologie e qualità degli alimenti.

Goodland R, 1995. The concept of environmental sustainability. Annu Rev Ecol Evol Syst 26:1-24.

Haas W, Krausmann F, Wiedenhofer D, Heinz M, 2015. How circular is the global economy?: An assessment of material flows, waste production, and recycling in the European Union and the world in 2005. J Ind Ecol 19:76577.

Hahladakis JN, Iacovidou E, 2018. Closing the loop on plastic packaging materials: What is quality and how does it affect their circularity? Sci Total Environ 630: 1394-400. 